\title{
Yönetici Hemşirelerin Örgüt Kültürünün Oluşumundaki Rolü
}

\author{
Melek KARATUZLA*
}

\begin{abstract}
$\ddot{O} \mathbf{z}$
Örgüt kültürü bir kurumun var olmasından itibaren oluşan ve şekillenen, bazı durumlar karşısında da değiştirilmek zorunda kalınan yönetim felsefesidir. Bu felsefenin oluşumunda en önemli görev ve sorumluluk kurum yöneticilerindedir. Bu çalışmanın amacı kurumsal bağlılı̆̆ı artırmada hastanelere özgü kimlik, kültür ve felsefeyi barındıran örgüt kültürünün oluşturulmasında, yönetici hemşirelerin rolünü literatür doğrultusunda incelemektir. Bu bağlamda hemşire, örgüt kültürü, yönetici hemşire ve yönetim anahtar kelimeleri ile tez, makale ve kitaplar taranmıştır. Sonuç olarak, yönetici hemşirelerin hastanenin örgüt kültürünün oluşturulmasında etkin rol almalarının, hemşirelerin motivasyonu, iş doyumu, sunmuş oldukları hizmet ve bakımın niteliği gibi önemli faktörler üzerinde etkili olduğu söylenebilir.
\end{abstract}

Anahtar Sözcükler: Hemşire, yönetici hemşire, örgüt kültürü, yönetim.

\section{The Role of Executive Nurses in the Development of Organizational Culture}

\begin{abstract}
Organizational culture is the management philosophy that is formed and shaped since the existence of an institution and has to be changed in some cases. The most important duty and responsibility in the formation of this philosophy is in the institution managers. The aim of this study is to examine the role of administrative nurses in the establishment of an organizational culture that includes hospital-specific identity, culture and philosophy in enhancing corporate loyalty. In this context, nurses, organizational culture, executive nurse and management keywords, thesis, articles and books were scanned. As a result, it can be said that the role of administrative nurses in the formation of the organizational culture of the hospital is effective on

Derleme Makale (Review Article)

Geliş / Received: 10.03.2020 \& Kabul / Accepted: 30.05.2020

DOI: https://doi.org/10.38079/igusabder.701491

* Öğr. Gör., Beykent Üniversitesi, Meslek Yüksekokulu, Anestezi Programı, İstanbul, Türkiye, E-posta: melekkaratuzla@beykent.edu.tr ORCID https://orcid.org/0000-0003-4727-3121
\end{abstract}


important factors such as the motivation of the nurses, job satisfaction, the quality of the service and care they offer.

Keywords: Nurse, nurse manager, organization culture, management.

\section{Giriş}

Her ülkenin sağlık sisteminde ayrı bir öneme sahip olan hastaneler birincil işlev bakımından tedavi bakım hizmeti sunar. Bir toplumda sağlıklı ve hasta bireylerin sağlığının korunması, geliştirilmesi ve devamlılığının sağlanması ile birlikte hastalık durumunda iyileştirilmesi gibi önemli görevler üstlenen hastaneler, yönetim açısından sağlam ve kaliteli olmalıdır ${ }^{1}$. Aynı zamanda hastaneler örgüt bazında hem kamusal liderlerle hem de toplumun baskın gruplarıyla karşılıklı etkileşimde olan kurumlardır. $\mathrm{Bu}$ bağlamda hastanelerin yönetimi oldukça zor ve karmaşıtır. Ancak dünya nüfusundaki hızlı artış, ortalama yaşam süresinin uzaması, sağlık bilgi seviyesinin ve paralelinde sağlık gereksinimlerinin artması, sağlık turizminin yaygınlaşması ve sağlık teknolojisinin ilerlemesi gibi sebepler hastane yönetiminin etkin, verimli ve kontrollü sağlanmasını gerekli kılmaktadır².

Etkin bir hastane yönetiminde hemşirelik hizmetlerinin varlığı yadsınamaz bir gerçektir. Bu durum hastanelerde hemşirelik hizmetlerinin doğru ve iyi bir şekilde yönetilmesinin gerekliliğini vurgulamaktadır ${ }^{1 .}$

Hastanelerin en kalabalık iş gören kitlesini oluşturan hemşireler sundukları kaliteli sağlık hizmeti ve hizmet alıcılarının memnuniyeti açısından örgüt başarısında büyük rol oynamaktadır. Ancak çalışma koşulları ve fiziki şartları iyi olmayan hemşirelerin kuruma karşı bağlılıkları olumsuz etkilenmekte ve bu da işten ayrılma niyetlerini artırmaktadırı ${ }^{1,3}$ Bostan ve Köse'nin (2011) üniversite hastanesinde çalışan 131 hemşire üzerinde yaptığı çalışmada, çalışma ortamlarının hemşirelerin fiziksel sağlıklarını gözetecek düzeyde olmadığı ve bu durumun hemşirelerin işten ayrılma düşüncelerini etkilediği sonucuna ulaşmıştır¹.

Hemşirelik hizmetlerinin iş yükü ve sorumluluklarının fazla olması hastane yönetiminin önemli bir kolu olan hemşirelik hizmetleri yönetim süreçlerine, değişken ve kompleks özellik kazandırmaktadır. Kuruma olan bağlılık ve kurumun kendine özgü kültür ve felsefesinin benimsenmesi kurumun her hemşiresi için gerekliliktir. Sorumlulukları ve 
görevlerin yüklediği ağırlık, kuruma olan bağlılık sayesinde iş tatmini, işi severek yapma ve motivasyona dönüşecektir ${ }^{4}$. Bu çalışmanın amacı, kurumsal bağlılığı artırmada hastanelere özgü kimlik, kültür ve felsefeyi barındıran örgüt kültüründe yönetici hemşirelerin rolünü literatür doğrultusunda incelemektir.

\section{Örgüt Kültürü}

Örgüt üyelerinin legal ve illegal iletişimi ile oluşmuş sosyal durum ve bu sosyal durumun bir sonucu niteliğinde oluşan kültürel yapı, kişilerin kendi ortamlarındaki davranışlarıyla sosyal bir gerçekliğe dönüşür. Bu sosyal durum bireylere ortak yaşam alanları sunarak kendi dünyalarının dışına çıkmalarını sağlar. Bununla birlikte bu sosyal yapı kişilere iş dünyasıyla ilgili konular, stratejiler, terimler ve planlar gösterir. Bu sayede çalışanlar aynı konular, kavramlar vb. ile ortak kültür ve değerlerin içinde sosyal alanlarını belli bir düzen içinde kurabilmektedirler. Aynı zamanda bu sosyal alan kişilerin farklı uyaranlara oluşturdukları cevapları da şekillendirmektedir. Buna göre örgüt kültürü kişilerin örgütten önceki yaşamlarına benzer örgüt içinde yeni bir sosyal alan oluşturmaları denebilir5,6. Tanım yapılacak olursa örgüt kültürü, kurum çalışanlarının belli bir zaman diliminde oluşturdukları kurum gelenekleri, artefaktları, kavramları ve normlarının tamamı şeklinde tanımlanabilir7.

Bir başka tanıma göre ise örgüt çalışanlarının kurum içi bütünleşme ve kurum dışı uyumlaştırma problemlerine çözüm yolları ararken, oluşturduğu, geliştirdiği, kurum için kabul edilebilir, kuruma kabul edilen yeni üyelere belirli şekillerde öğretilebilen kavramlardır8,9. Kültür bir organizasyonun kişilik ve kimliğini temsil eder ve hem çalışanların memnuniyeti hem de organizasyonun başarısı üzerinde önemli bir etkiye sahiptir. Örgüt kültürü bir organizasyonu bir arada tutan sosyal bir bütünleştiricidir ${ }^{10}$.

Örgütsel hedeflere ulaşmada ilk olarak yapılması gereken, çalışanları bu hedefe yönlendirmektir. Çalışanların örgütle bağ kurması, bütün organizasyonlarda etkinlik açısından önem arz eder. Örgütün içsel ve dışsal unsurlarla uyumunu sağlayan ise organizasyona özgü kültürdür. Örgüte ait gelenekler, normlar ve kültürel özelliklerini içselleştiren yani örgüt içi ve örgüt dışı unsurlara uyum sağlayan çalışanlar, yöneticinin beklentilerine katkıda bulunabilir ${ }^{11}$. Sonuç olarak örgütsel bağlılığı olan, yüksek performans sergileyen ve etkin çalışanların bulunduğu örgütün hizmet kalitesi de artacaktır ${ }^{1}$. 
Organizasyonlar farklı kültür desenlerine sahip çalışanlardan oluşmaktadır. $\mathrm{Bu}$ çalışanlar, mesleki görevleri doğrultusunda belli ölçütlerle bir araya gelerek, oluşturdukları grubun doğal bir sonucu olarak diğer organizasyonlardan farklı yeni bir ortak inanç ve değerler sistemi meydana getirebilmektedirler ${ }^{4,12}$. Sahip oldukları kültürden farklı, o örgüte özgü bu değerler sistemi sayesinde örgüt çalışanları, örgütsel ve bireysel boyutta iyi ve kötü, yapılması ve yapılmaması gerekenleri, hedeflenen ve hedeflenmeyeni öğrenmiş olurlar. Bununla birlikte bu değerler sistemi motivasyon kaynağı olduğu kadar organizasyonun amaçlarını, politikalarını ve stratejilerini gösteren bir kılavuz niteliği de taşır. Bu doğrultuda örgütsel başarının devamlılı̆̆ı örgütsel değer ve inanç sisteminin oluşturulmasına ve çalışanlar tarafından bu sisteme gösterilen uyuma bağlıdır.

Örgüt kültürünün bireysel ve örgütsel performansta yarattığı olumlu etkiler düşünüldüğünde ${ }^{13,14}$, hastanelerde örgüt kültürünün önemini anlamak, insan kaynakları ve halkla ilişkilerde etkilerini kavramak, beklentileri karşılayacak bir sağlık hizmeti sunumu için örgüt kültürünü oluşturmak, kaliteli ve etkin bir hastane yönetiminde olmazsa olmazlardandır. Bu hedef doğrultusunda hastanelere özgü örgüt kültürü oluşturma ve yönetiminde yöneticilere düşen görevler, hastanenin mevcut örgüt kültürünün nasıl olduğunu ya da nasıl olması gerektiğini, hedeflenen örgüt kültürünün ihtiyaçlarının neler olduğunu ve nasıl giderileceğini, örgüt kültürünün değiştirilmesinde hangi düzeyden ve nereden başlanacağı gibi konuların irdelenmesidir ${ }^{15,16}$.

Hastanelerde örgüt kültürünün fonksiyonları; örgütün kültürel değerlerinin kuşaktan kuşağa aktararak, kurumun devamlılı̆̆ını sağlamak, örgüte kimlik ve kişilik kazandırmak, çalışanların motivasyonunu sağlamak, kültürün sunduğu tarihsel olaylar ve haritalar, çalışanlara, karşılaştıkları durumları nasıl çözecekleri konusunda yardımcı olmak, kurumlara ihtiyaç anında yapı değişikliğinde yardımcı olmak, bireysel ihtiyaçlar ile kaliteli hizmeti bütünleştirmek, örgütlerin hedeflerine ulaşmasında ve devamlılı̆̆ının sağlanmasında işlevsel olmaktır.

Hastaneler örgütsel amaçlara ulaşmada örgüt çalışanları tarafından paylaşılan değer, inanç ve tutumlarla, örgütsel düzeyde kendilerini geliştirerek sağlam bir örgüt kültürü oluşturabilir. Örgütün kurumsallaşmasına katkı sağlayacak bir örgüt kültürünün oluşturulmasında, hastanelerde özümsenen ve paylaşılan değerlerin grup davranışlarına yansıtılması yöneticilerin performansıyla ölçülebilir ${ }^{17}$. Örgütsel değerler işgücünün diğer 
sektörlere göre daha önemli olduğu hastane işletmelerinde örgüt kültürünü destekleyen en önemli unsurlardır. Bu yüzden yöneticiler, örgüt kültürünün oluşturulmasında öncelikle örgütsel değerlere yoğunlaşmalıdır ${ }^{18}$. Hizmet verici rolünde çalışanlarla hizmet alıcı rolünde hastaların sürekli iç içe olduğu hastane işletmelerinde, iş tatmini ne kadar düşükse sunulan hizmetin kalitesi ve hasta memnuniyeti de o derecede düşer. $\mathrm{Bu}$ bağlamda hasta memnuniyeti ile iş görenin, iş ve kurumdan memnun olması ile ilişkili olduğu söylenebilir ${ }^{5,19}$.

\section{Örgüt Kültürünün Oluşumu}

Örgüt kültürü; oluşturulması, sürdürülmesi ve değişimi bir bütün halinde süregelen dinamik bir süreçtir ve bu süreçte en büyük rol yöneticinin kendisindedir ${ }^{20,21}$. Liderlik ve örgüt ilişkisinde karşılıklı etkileşimi olan iki taraflı bir ilişkiden söz edilebilir. Örgüt kültürü liderlik tarzını ve gösterilen davranışları etkilerken; lider de örgüt kültürü ve örgütsel değerler üzerinde etki gösterir ${ }^{22,23}$. Lider örgüt kültürünü oluştururken, örgütün sahip olması gereken vizyon, misyon, strateji ve felsefesine göre amaçlarını belirler. Bunların yanı sıra inançlar, semboller, ortak dil gibi değerlerle de örgütsel yaşamın şekillenmesini sağlar ${ }^{24}$.

Kurum tepe yöneticisi örgüt kültürünü öğrenip uygulayabilecek kişidir. Bu yönetici amaçlarını davranışlara, davranışlarını alışkanlıklara, alışkanlıklarını kişiliğe ve kişiliğini kültüre dönüştürebilir. Bu kültür örgüt kültürünün de oluşumunda rol alır. $\mathrm{Bu}$ yüzden kurum liderinin davranışları çok önemlidir. Kurumun temsiliyetini üstlenen lider kültürel çeşitliliği yönetirken ve etkileşimi sağlarken kullandığı liderlik becerilerini dikkatli seçmelidir. Ayrıca liderler örgütün kültürünün etkililiğini, ne zaman ve nasıl dönüştürülmesi gerektiğine de hâkim olmalıdır. Özetle örgüt kültürü yönetim yetkililiğinin yanı sıra liderlik ister ${ }^{25}$.

Tablo 1. Örgüt kültürünün oluşumu ve sonuçları²

\begin{tabular}{|l|l|l|}
\hline Kaynaklar & Örgüt külttürü & Sonuçlar \\
\hline -Sosyal değerler & -Örgütsel değerler sistemi & -Örgüt yapısı \\
-Dış etkiler & ve Uygulama & -Birey-örgüt bütünleşmesi \\
-İç koşullar & & -Statü farklllıklarının belirlenmesi \\
-Yönetim & & -İdeoloji ve semboller \\
-Teknoloji & & -Sosyal faaliyetler \\
-Gelenekler & & \\
\hline
\end{tabular}


Tablo 1'de görüldüğü üzere örgüt kültürünü oluşturan farklı kaynaklar vardır. Örgüt kültürünü oluşturan bu kaynakların kurum üzerindeki etkisini davranış güvenliğini oluşturma, bir grup olma ve aidiyet duygusunu geliştirme, örgüt olma duygusunu destekleme, temel kültürel değerlere sahip çıkma ve güçlendirme, örgütsel bağlılığı geliştirme, kurum içerisinde birlik ve beraberliği sağlama, motivasyonu sağlama, yeni işe başlayanların uyumunu kolaylaştırma, sadece kültürel değil duygusal bütünleşmeyi de destekleme, kurumun gelişim sürecinin açıklanması için bir mekanizma oluşturma gibi siralamak mümkündür:

Örgüt kültürünün oluşumunu etkileyen diğer etmenler ise kurumun fiziki ortamı, şartları ve kültür adına yapılması gerekenlerdir. Hem örgüt üyelerinin hem de hizmet alıcıları olarak hastaların memnuniyetini artıran olumlu kültürler, çalışanların meslektaş iletişimi ve etkileşimini etkileyerek, kişisel memnuniyet elde etmelerini ve kurumsal amaçlar doğrultusunda çalışmalarını sağlayabilir²7.

Luthans (2002) ve Schein (2010) da örgüt kültürü oluşumunda birbirini izleyen adımları şu şekilde sıralamaktadır: Bireyler kurucu olma düşüncesiyle amaçlarını faaliyete geçirir, Bireyler hedefler çerçevesinde kurucu, kendisiyle ortak düşünce içinde olan bir grup çalışanı bir araya getirir ve yine hedefler çerçevesinde idealler oluşturulur. Bu sayede kurumun faaliyetleri amaçlar doğrultusunda şekillendirilmiş olur. Kuruma farklı çalışanlar da dâhil edilir ve bu sayede ortak inanç, değer ve birikimler oluşmaya başlar ${ }^{8,28}$.

\section{Yönetici Hemşirelerin Örgüt Kültürü Oluşumundaki Etkileri}

Kurum veya kuruluşun yönetim ve fonksiyonel işleyişinden sorumlu olan yöneticiler, toplumsal ünü veya sosyal statüsü sebebiyle önde olması veya birilerini yönetmesi ya da birilerine davranışsal örnekler oluşturabilmesi, başlatabilmesi, idare etmesi ve örgütleyebilmesi bir birikimin sonucu olarak önümüze çıkar. Bu birikim tamamen ve yalnızca öğrenilmiş bir birikim değil, doğuştan gelen, mesleksel bir süreç veya bir bütün halinde olabilir6.

Tepe yöneticiler örgüt dışı faktörlere karşı, hedeflerini, misyonu ve çıkarlarını düşünerek kararlar alır ve aldığı kararlarla örgütün hedefleri doğrultusunda çalışanları etkiler 6 . Örgütün hedefleri ile iş görenlerin hedeflerinin bütünleştirilmesi bir yöneticiye düşen 
önemli görevlerdendir. Bu görev ancak iyi bir örgüt kültürü sayesinde gerçekleştirilebilir7.

"Esneklik, informalite, istikrar, uyum, tahmin edebilirlik, destekleyici olma, yenilikçi olma, risk alma, inisiyatif alma, dikkatli olma, özerklik, kurallara bağlılık, bireysel sorumluluk alma, analitik düşünme, çalışan güvenliği, ayrıntılara dikkat etme, düşük çatışma düzeyi, karmaşaya karşı koyma, işe istekli olma, tek bir örgütsel kültürü vurgulama, kaliteye önem verme, insan merkezli olma, sosyal sorumluluk alma, bireysel haklara saygılı olma, sonuç odaklı olma, yüksek düzeyde örgütlenme ve tolerans”7 gibi kavramlar örgüt kültürünün değerleridir ve bu kavramlar etkinlik ve yönetim felsefesini yansıtır. Aynı zamanda bu faktörler iyi bir yöneticide olması gereken nitelik ve yönleri de ifade etmektedir. Bu faktörlere sahip bir örgütsel kültür, örgüte güçlü ve güvenilir bir aile olmayı sunar ve örgütün faaliyet gösterdiği tüm alanlarda ve yönetimde etkilidir7.

Yöneticilik çalışanların yönetilmesiyle birlikte kurum kültürünün de yol haritasının belirlenmesini ve denetimini sağlamaktadır. Bu doğrultuda yöneticilikle kurum kültürünün bütünleştirici etkisi önem arz etmektedir5.

Örgüt kültürü, yönetimi etkilediği kadar kurum çalışanlarını da etkiler. Bireyler kurum kültüründen ayrı düşünülemez. Bu bağlamda yönetim davranışı, insanoğlunun kültürle bağlantısı devam ettikçe kültürel faktörlerden etkilenir6

Örgüt kültürünün oluşmasında en tepedeki yöneticinin rolü büyüktür. Yöneticinin onaylamadığı hiçbir davranış ya da değer kuruma kolay kolay giremez ve yayılamaz. Ancak yöneticinin kabul ettiği değerler kurumda kabul görür. Bu amaçla tepe yönetici gerek iletişimi denetleme, gerekse ödül sistemi veya ceza sistemini çalıştırabilir. Yöneticilerden bu kadar fazla etkilenen kurum kültürü, haliyle yöneticilerin kişiliklerini de yansıtır. Hatta kurumun kültürü bütün yöneticilerin özelliklerine göre nitelik sahibi olabilir. Bunun sonucunda bazı olumsuzluklar da kültüre yansıyabilir. Örneğin tepe yönetici ya da onu izleyen diğer yöneticilerin davranış veya kişilik bozuklukları varsa, etkileme düzeyine göre örgüt kültürü negatif yönde gelişebilirø ${ }^{6}$.

Yönetim uygulamaları ve kurum kültürünün yapısal durumu sadece tepe yönetici ya da diğer yöneticilerden etkilenmez. Kurumun normal faaliyet alanlarına göre de nitelik kazanabilir. Hastaneler gibi hizmet türü ve özellikleri gittikçe karmaşık bir yapıya bürünen kurumlarda yönetici ve kurum kültürü günden güne daha önemli hale 
gelmektedir. Hizmet edilen grubun insan faktörü olması, teknolojinin ve iş ile iş gücünde oluşan değişimler, yönetici ve çalışanların liderlik özellikleri taşımalarını ve örgüt kültürünün yönetimde temel araç haline getirilmesini gerekli kılmaktadır. Bu faktörler aynı zamanda örgütün faaliyetlerinin oluşum, yönetim ve gerektiğinde de değişiminde rol oynayan belirleyicilerdendir5.

Temelinde güçlü örgüt kültürleri olan hastanelerin yöneticileri açısından kurumun sahip olduğu kültür yönetsel araç olarak işlerin kolaylaşmasını sağlayacaktır. Örgütsel uyumun artmasıyla birlikte işin kalitesi de artacaktır. Hastanelerde örgüt kültürü oluşturulurken hizmet sunulan alan olarak insan odaklı, esnek, yeniliklere açı, gelişmelere uyum sağlayan dinamik değerler ölçüt alınmalıdır. Yapılan ulusal çalışmalar hastanelerde örgüt kültürü oluşturmada yöneticilerin olumlu bir tavır sergilediklerini ortaya koymuştur 5 ,29.

Örgüt kültürü bir kurumda iş gören motivasyonunu sağlayan iç ve dış unsurlar arasında en önemlisidir. Çünkü iş gören motivasyonunda dış etmenlerden çok kişinin iç dünyasında var olan güdüler ve davranışlar etkindir. Çalışan motivasyonun sağlanması, kurum amaçlarına ulaşmada rol oynamaktadır. Bununla birlikte her kurum kendine ait bir kültüre sahiptir ve bu kültür iş gören davranışlarını, işin kalitesini ve işin algılanma durumunu doğrudan etkilemektedir3o.

San Park ve Kim (2009) Kore'deki devlet hastanesi hemşireleri üzerinde yaptığı çalışmasında örgüt kültürünün, hemşirelerin iş memnuniyetini sağlayabileceğini, maliyeti düşürebileceğini, istikrarlı ve nitelikli bir işgücü sağlamaya yardımcı olabileceğini vurgulamışlardır³1.

Hastanede profesyonel düzeyde hizmet veren tüm grupların kurumun kültürel ve yönetsel alanlarını oluşturma, varlığını devam ettirme ve değiştirmede önemli rolleri bulunmaktadır. Hastanelerin en geniş gruplarını oluşturan hemşirelik hizmetlerinin, sağlı̆̆ı koruma geliştirme, hastalık halinde iyileştirme, hasta ve ailesiyle iletişim ve bakımını sağlama rollerini üstlenmişlerdir. Hemşireler, üstüne düşen bu sorumlulukları yerine getirirken, kurumun felsefesini, standartlarını, bakım ve tedavi ilkelerini, kurumun amaçlarını bilmek ve hizmet sunarken bu faktörler çerçevesinde çalışmak durumundadır. Bu durum hemşirelik hizmetlerinin kurumun kültür ve yönetsel alanlarını çokça etkileyebileceğinin göstergesidir. Hastanelerde farklı yönetsel 
pozisyonlarda bulunan hemşirelerin, gösterdikleri liderlik davranışlarıyla bakım ve eğitim üzerindeki olumlu değişikliklerle birlikte, mesleki gelişmeleri hareketlendirir, sunulan bakımın kalitesini ve verimliliğini artırır, örgütsel kültürü güçlendirerek sistemin yönünü değiştirebilir²4.

Kelez (2008)' in hemşirelerin örgüt kültürü algıları ile yöneticilerin liderlik davranışları arasındaki ilişkiyi belirlemek amacıyla yaptığı tez çalışmasında, Hemşirelerin örgüt kültürü algılarının, demokratik ve katılımcı yönetime sahip hastanelerde, sömürücüotokratik ve yardımsever-otokratik olan hastanelerden anlamlı oranda yüksek olduğu sonucuna ulaşılmıştır ${ }^{24}$.

Hizmet sunucu rolündeki hemşirelerle, hizmeti alan hastaların sürekli formal ve informal iletişim halinde olduğu sektörde, etkin bakım ve hasta memnuniyeti hemşirelerin iş doyumu ve kurumsal tatminleriyle doğrudan ilişkilidir. Bu yüzden yönetici hemşirelere düşen görev, kurum kültürünü oluşturma, geliştirme ve gerektiğinde değiştirilmesinde etkin rol almalarıdır. Yönetici hemşirelerin sergilediği liderlik davranışları sayesinde hemşirelerin sahip oldukları, tutum, değer ve davranışlar ile örgütsel değerler bütünleştirilerek, sunulan sağllk hizmetinin kalitesini artıracak bir örgüt kültürü oluşturulabilecektir. Bu yüzden yönetim pozisyonlarındaki vizyon sahibi hemşireler, örgüt kültürünün oluşturulma aşamasında değişime açık ve risk alabilecek cesarette olmalıdırlar. Ayrıca çalışanlara yönelik empati kurabilmeli ve olumlu benlik saygısı kazanmalarını sağlamalıdır. Yöneticiler sahip oldukları liderlik yaklaşımlarıyla da yeniliklere açık, ekip çalışmasını ve iletişimini kolaylaştıran, problem çözme becerilerini geliştirmiş olmaları gerekmektedir ${ }^{24}$.

Hemşireler mesleki bütünleşmeden kaynaklanan pozitif kültürel değerlere sahiptirler. Hemşirelik liderlerinin ve çalışanlarının bu durumdan faydalanmak, örgütsel hedefleri, insancıl değerleri ve hasta savunuculuğu rolünü birleştiren bir kültür oluşturmak amacıyla beraber çalışmaları gerekir. Bu hedef doğrultusunda atılacak ilk adım, lider konumundaki hemşirelerin, organizasyonun özelliklerini ve kimliğini barındıran bir kültürü olduğunu ve insanların iş alanlarındaki davranışlarını ve ilişkilerini bu kültür doğrultusunda şekillendirdiklerini kabul etmeleri gerekir. Örgütün değerleri açıç̧a ifade edildikten sonra yapıcı kültürler inşa etmek, lider konumundaki hemşirelerin değerleri ile örgütün vizyonunu bütünleştirmeyi gerektirir. Vizyon çalışanların hedefe yönelik çabalarını geliştirerek yapıcı örgüt kültürünün temelini sağlamış olur. Bir başka ifadeyle, 
anlaşılabilir ve iyi planlanmış bir vizyon hemşirelere sadece rehberlik etmez, aynı zamanda çalışmalarına bir amaç duygusu ve ilham kaynağı sağlar²7.

Hewison (1999) çalışmasında örgüt kültürünün, karmaşı sağlık bakım organizasyonlarının daha iyi anlaşılmasını ve dolayısıyla etkili yönetimini sağlaması bakımından hemşire yöneticileri için yararlı bir kavram olabileceği öne sürülmektedir32.

\section{Sonuç ve Öneriler}

Bir kurumun varlığını devam ettirebilmesi, sunduğu hizmetin etkin ve kalitesi, çalışanların iş tatmini, motivasyon ve memnuniyetlerinin sağlanması, hizmet sunulan grubun yine memnuniyet düzeyleri kurumun sahip olduğu örgüt kültürü ile doğrudan ilişkilidir. Örgüt kültürü aynı zamanda çalışanlar arasında güçlü bir bağ kurarak takım ruhunu geliştirebilir. Hastanelerin en geniş grubunu oluşturan hemşirelerin ve hemşirelik hizmetlerini yöneten yönetici hemşirelerin, kurumun sürekli değişen ve gelişen dinamik çevresine uyum sağlamaları sunulan hizmetin kalitesi açısından önemlidir. Bununla birlikte örgüt dışındaki faktörlerde kurumun sürekliliğini tehdit edebilir. Profesyonel bir grup olarak hemşire yöneticilerin örgüt kültürünün oluşumunda aktif rol almaları, hemşirelerin motivasyon kaynağı olacak ve oluşturulan kültürü benimseyip, davranışları şekillendirmeleri kolaylaşacaktır. Bu sayede hem kurumun sürekliliği sağlanmış olacak hem de sunulan hizmetin kalite ve verimliliğinde düşüş olmayacaktır. Aynı zamanda iş tatmini ve motivasyonu da artırarak kişilerin kurumu sahiplenmelerini sağlayacaktır.

Sonuç olarak incelenen çalışmalar hastanelerin örgüt kültüründe profesyonel bir grubu temsil eden yönetici hemşirelerin rol almaları gerektiğini göstermiştir.

\section{KAYNAKÇA}

1. Bostan S, Köse A. Hemşirelerin yönetsel hizmetleri ve çalışma ortamlarını değerlendirmesi-bir üniversite hastanesi örneği. Clinical and Experimental Health Sciences. 2017;1(3):176-183.

2. Özgener Ş, Küçük F. Hastanelerde modern yönetim felsefesinin verimliliğe etkisi: Gevher Nesibe hastanesinde bir uygulama. Selçuk Üniversitesi Sosyal Bilimler Enstitüsü Dergisi. 2008;20:543-560. 
3. Kanbay A. Hemşirelerin iş doyumu ve örgütsel bağlılı̆̆ı [Yüksek lisans Tezi]. Hemşirelik bölümü, Haliç Üniversitesi, İstanbul, Türkiye, 2010.

4. Karadağ M, Akman N, Demir C. Hemşirelik hizmetlerinde yönetsel ve örgütsel sorunlar. Anadolu Hemşirelik ve Sağhk Bilimleri Dergisi. 2013;16(1):16-26.

5. Karahan A. Çalışanların örgüt kültürünü algılamalarına yönelik ampirik bir çalışma. Selçuk Üniversitesi Sosyal Bilimler Enstitüsü Dergisi. 2008;20:457-478.

6. Aydınlı Hì. Örgüt kültürünün yönetim açısından önemi. Bilgi Sosyal Bilimler Dergisi. 2003;2:79-99.

7. Şahin A. Örgüt kültürü-yönetim ilişkisi ve yönetsel etkinlik. Maliye Dergisi. 2010;159:21-35.

8. Schein EH. Organizational Culture And Leadership. 4 th edition. United states of America: John Wiley \& Sons, 2010.

9. Kantek F, Baykal Ü. Hemşirelik yüksekokulları için örgüt kültürü ölçeğinin geliştirilmesi. Anadolu Hemşirelik Ve Sağhk Bilimleri Dergisi. 2008;11(2):29-37.

10. Kane-Urrabazo C. Management's role in shaping organizational culture. Journal of nursing management. 2006;14(3):188-194.

11. Berberoğlu G. Örgüt kültürü ve yönetsel etkinliğe katkısı. Anadolu Üniversitesi İktisadi ve İdari Bilimler Fakültesi Dergisi. 1990;8(1):153-161.

12. Bilazer FN, Konca GE, Uğur S, Uçak H, Erdemir F, Çıtak E. Türkiye’de hemşirelerin çalışma koşulları. Türk hemşireler derneği (THD). Ankara: Odak Ofset Matbaacılık, 2008.

13. Akkoç İ, Çalişkan A, Turunç Ö. Örgütlerde gelişim kültürü ve algılanan örgütsel desteğin iş tatmini ve iş performansına etkisi: güvenin aracıllk rolü. Yönetim ve Ekonomi: Celal Bayar Üniversitesi İktisadi Ve İdari Bilimler Fakültesi Dergisi. 2012;19(1):105-135.

14. Örücü E, Ayhan AGN. Örgüt kültürü (Muğla üniversitesi örneği). Eskişehir Osmangazi Üniversitesi Sosyal Bilimler Dergisi. 2001;2(2):87-105. 
15. İnanoğlu S, Erigüç G. Örgüt kültürü: personelin ve yöneticilerin değerlendirmeleri açısından bir karşılaştırma. Hacettepe Sağhk İdaresi Dergisi. 2000;5(4):1-25.

16. Eskiyörük D, Turan M. Halkla ilişkiler uygulayıcıları rol modellerinde örgüt kültürünün etkisi ve hastane işletmelerinde bir uygulama. Gazi Üniversitesi İktisadi ve İdari Bilimler Fakültesi Dergisi. 2010;14(2):19-50.

17. Willcocks SG. Organizational analysis: a health service commentary. Leadership \& Organization Development Journal. 1994;15(1):29-32.

18. Brooks I. Leadership of a cultural change process. Leadership \& Organization Development Journal. 1996;17(5):31-37.

19. Akıncı Z. Turizm sektöründe iş gören iş tatminini etkileyen faktörler: beş yıldızlı konaklama işletmelerinde bir uygulama. Akdeniz İIBF Dergisi. 2002;4:1-25.

20. Baytok A. Hizmet işletmelerinde örgüt kültürünün oluşturulmasında liderin rolü [Doktora Tezi]. İşletme Anabilim Dalı, Afyon Kocatepe Üniversitesi, Afyonkarahisar, Türkiye, 2006.

21. Tsui AS, Zhang ZX, Wang H, Xin KR, Wu JB. Unpacking the relationship between ceo leadership behavior and organizational culture. The Leadership Quarterly. 2006;17(2):113-137.

22. House R, Javidan M, Hanges P, Dorfman P. Understanding cultures and implicit leadership theories across the globe: an introduction to project globe. Journal of World Business. 2002;37(1):3-10.

23. Bakan İE. ‘Örgüt kültürü’ ve 'liderlik’ türlerine ilişkin algılamalar ile yöneticilerin demografik özellikleri arasındaki ilişki: bir alan araştırması. Karamanoğlu Mehmetbey Üniversitesi Sosyal ve Ekonomik Araştırmalar Dergisi. 2008;1:1340.

24. Kelez A. Hemşirelerin örgüt kültürünü ve yöneticilerin liderlik davranışını algılamaları [Yüksek Lisans Tezi]. Hemşirelikte Yönetim Anabilim Dalı, Marmara Üniversitesi, İstanbul, Türkiye, 2008. 
25. Erdem O, Dikici AM. Liderlik ve kurum kültürü etkileşimi. Elektronik Sosyal Bilimler Dergisi. 2009;8(29):198-213.

26. Tosi HL, Rizzo JR, Carroll SJ. Managing Organizational Behavior. Malden, Kitle: Blackwell; 1999.

27. Wooten LP, Crane P. Nurses as implemented of organizational culture. Nursing Economics. 2003;21(6):275.

28. Luthans F. Positive organizational behavior: developing and managing psychological strengths. Academy of Management Perspectives. 2002;16(1):5772.

29. Timurtaş M. Hastanelerde örgüt kültürü ile bilgi ifşası ilişkisinin değerlendirilmesi [Yükssek Lisans Tezi]. Sağlık Yönetimi Anabilim Dalı, Marmara Üniversitesi, İstanbul, Türkiye, 2018.

30. Doğan EA. Örgüt kültürünün çalışan motivasyonuna etkileri: belediyecilik sektöründe bir uygulama [Yüksek Lisans Tezi]. İşletme Anabilim Dalı, İstanbul Ticaret Üniversitesi, İstanbul, Türkiye, 2015.

31. San Park J, Kim TH. Do types of organizational culture matter in nurse job satisfaction and turnover intention? Leadership in Health Services. 2009;22(1):20-38.

32. Hewison A. Organizational culture: a useful concept for nurse managers? Journal of Nursing Management. 1996;4(1):3-9. 